\title{
High-Order Sliding-Mode Control of Variable-Speed Wind Turbines
}

\author{
Brice Beltran, Tarek Ahmed-Ali, and Mohamed El Hachemi Benbouzid, Senior Member, IEEE
}

\begin{abstract}
This paper deals with the power generation control in variable-speed wind turbines. These systems have two operation regions which depend on wind turbine tip speed ratio. A high-order sliding-mode control strategy is then proposed to ensure stability in both operation regions and to impose the ideal feedback control solution in spite of model uncertainties. This control strategy presents attractive features such as robustness to parametric uncertainties of the turbine. The proposed slidingmode control approach has been validated on a 1.5-MW threeblade wind turbine using the National Renewable Energy Laboratory wind turbine simulator FAST (Fatigue, Aerodynamics, Structures, and Turbulence) code. Validation results show that the proposed control strategy is effective in terms of power regulation. Moreover, the sliding-mode approach is arranged so as to produce no chattering in the generated torque that could lead to increased mechanical stress because of strong torque variations.
\end{abstract}

Index Terms-High-order sliding mode, power generation control, wind turbine.

\section{NOMENCLATURE}

$v \quad$ Wind speed (in meters per second).

$\rho \quad$ Air density (in kilograms per cubic meter).

$R \quad$ Rotor radius (in meters).

$P_{a} \quad$ Aerodynamic power (in watts).

$T_{a} \quad$ Aerodynamic torque (in newton-meters).

$\lambda \quad$ Tip speed ratio.

$C_{p}(\lambda)$ Power coefficient.

$C_{q}(\lambda)$ Torque coefficient.

$\omega_{r} \quad$ Rotor speed (in radians per seconds).

$\omega_{g} \quad$ Generator speed (in radians per seconds).

$T_{g} \quad$ Generator electromagnetic torque (in newton-meters).

$T_{\text {ls }} \quad$ Low-speed torque (in newton-meters).

$T_{\mathrm{hs}} \quad$ High-speed torque (in newton-meters).

$K_{g} \quad$ Generator external damping (in newton-meters per radian-second).

$K_{r} \quad$ Rotor external damping (in newton-meters per radian-second).

$J_{r} \quad$ Rotor inertia (in kilogram-square meter).

$J_{g} \quad$ Generator inertia (in kilogram-square meter).

$J_{t} \quad$ Turbine total inertia (in kilogram-square meter).

$K_{t} \quad$ Turbine total external damping (in newton-meters per radian-second).

Manuscript received January 13, 2008; revised September 4, 2008. First published October 31, 2008; current version published August 12, 2009.

The authors are with the Laboratoire Brestois de Mécanique et des Systèmes, University of Brest, 29238 Brest Cedex 03, France (e-mail: brice.beltran@dga. defense.gouv.fr; m.benbouzid@ieee.org).

Color versions of one or more of the figures in this paper are available online at http://ieeexplore.ieee.org.

Digital Object Identifier 10.1109/TIE.2008.2006949

\author{
$B_{r} \quad$ Rotor external stiffness (in newton-meters per \\ radian-second). \\ $B_{g} \quad$ Generator external stiffness (in newton-meters per \\ radian-second). \\ $B_{t} \quad$ Turbine total external stiffness (in newton-meters per \\ radian-second).
}

\section{INTRODUCTION}

W IND ENERGY conversion is the fastest growing energy source among the new power generation sources in the world, and this trend should endure for some time. At the end of 2006, the total U.S. wind energy capacity had grown to $11603 \mathrm{MW}$ or enough to provide the electrical energy needs of more than 2.9 million American homes. Wind capacity in the United States and in Europe has grown at a rate of 20\%-30\% per year over the past decade (Fig. 1). Despite this rapid growth, wind currently provides less than $1 \%$ of total electricity consumption in the United States. The vision of the wind industry in the United States and in Europe is to increase wind fraction of the electrical energy mix to more than $20 \%$ within the next two decades [1].

Harnessing wind energy for electric power generation is an area of research interest, and nowadays, the emphasis is given to the cost-effective utilization of this energy aiming at quality and reliability in the electricity delivery [2]. During the last two decades, wind turbine sizes have been developed from $20 \mathrm{~kW}$ to $2 \mathrm{MW}$, while even larger wind turbines are being designed. Moreover, a lot of different concepts have been developed and tested [3].

In fact, variable-speed wind turbines (VSWTs) are continuously increasing their market share, since it is possible to track the changes in wind speed by adapting shaft speed and thus maintaining optimal power generation. The more VSWTs are investigated, the more it becomes obvious that their behavior is significantly affected by the control strategy used. Typically, VSWTs use aerodynamic controls in combination with power electronics to regulate torque, speed, and power. The aerodynamic control systems, usually variable-pitch blades or trailingedge devices, are expensive and complex, particularly when the turbines are larger. This situation provides a motivation to consider alternative control approaches.

The main control objective of VSWT is power efficiency maximization. To reach this goal, the turbine tip speed ratio should be maintained at its optimum value despite wind variations. Nevertheless, control is not always aimed at capturing as much energy as possible. In fact, in above rated wind speed, the captured power needs to be limited. Although there are 


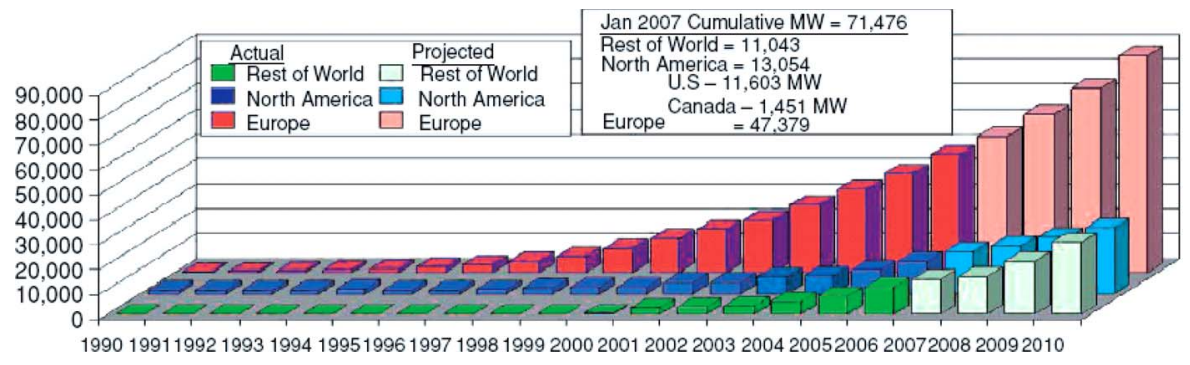

Fig. 1. Worldwide growth of wind energy installed capacity [1].

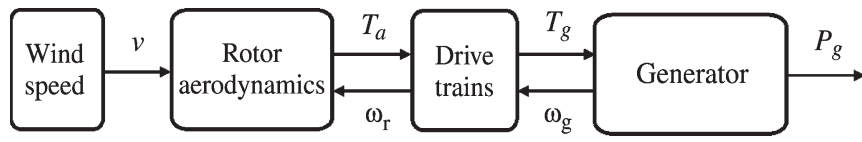

Fig. 2. VSWT global scheme.

both mechanical and electrical constraints, the more severe ones are commonly on the generator and the converter. Hence, regulation of the power produced by the generator (i.e., the output power) is usually intended, and this is the main objective of this paper.

\section{Wind TURBine Modeling}

The global scheme for VSWT is given by Fig. 2. The system modeling is inspired from the study in [4] and [5]. Moreover, a fixed pitch VSWT, which is considered in this paper, could be schematically represented by Fig. 3 .

The aerodynamic power $P_{a}$ captured by the wind turbine is given by

$$
P_{a}=\frac{1}{2} \pi \rho R^{2} C_{p}(\lambda) v^{3}
$$

where $C_{p}$ represents the wind turbine power conversion efficiency. It is a function of the tip speed ratio $\lambda$ as well as the blade pitch angle $\beta$ in a pitch-controlled wind turbine. $\lambda$ is defined as the ratio of the tip speed of the turbine blades to wind speed and is given by

$$
\lambda=\frac{R \omega_{r}}{v} .
$$

The $C_{p}-\lambda$ characteristics, for different values of the pitch angle $\beta$, are shown in Fig. 4. This figure indicates that there is one specific $\lambda$ at which the turbine is most efficient.

Normally, a VSWT follows the $C_{p \max }$ to capture the maximum power up to the rated speed by varying the rotor speed to keep the system at $\lambda_{\text {opt }}$. Then, it operates at the rated power with power regulation during high wind periods by active control of the blade pitch angle or passive regulation based on aerodynamic stall [6].

The rotor power (aerodynamic power) is also defined by

$$
P_{a}=\omega_{r} T_{a} .
$$

Moreover

$$
C_{q}(\lambda)=\frac{C_{p}(\lambda)}{\lambda}
$$

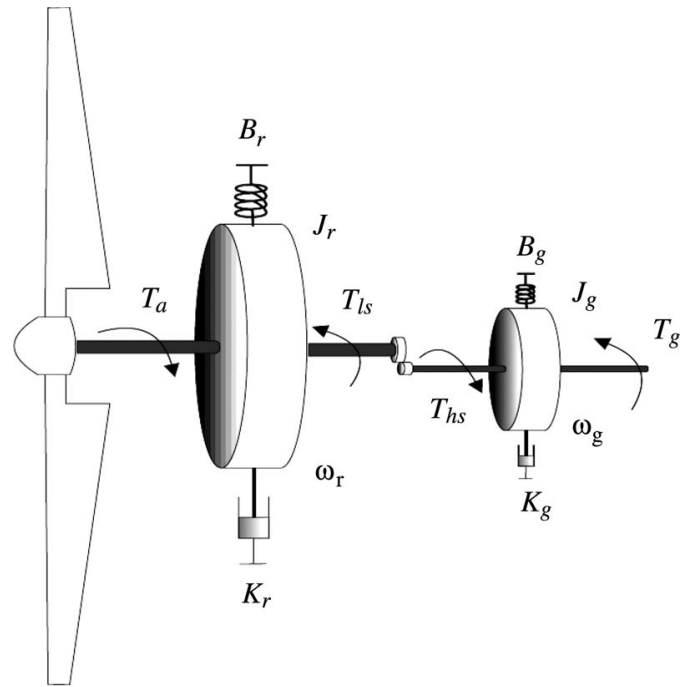

Fig. 3. Wind turbine drive train dynamics.

It comes then that the aerodynamic torque is given by

$$
T_{a}=\frac{1}{2} \pi \rho R^{3} C_{q}(\lambda) v^{2}
$$

and the optimum torque by

$$
T_{\mathrm{opt}}=k_{\mathrm{opt}} \omega^{2}, \text { with } k_{\mathrm{opt}}=\frac{1}{2 \lambda_{\mathrm{opt}}^{2}} \rho \pi R^{5} C_{q \max }
$$

where $\lambda_{\text {opt }}$ is the optimal tip speed ratio.

According to Fig. 3, the aerodynamic torque $T_{a}$ will drive the wind turbine at the speed $\omega_{r}$. The low-speed torque $T_{\mathrm{ls}}$ acts as a braking torque on the rotor. The generator is driven by the highspeed torque $T_{\mathrm{hs}}$ and braked by the generator electromagnetic torque $T_{g}$. Through the gearbox, the rotor speed is increased by the gearbox ratio $n_{g}$ to obtain the generator speed $\omega_{g}$ while the low-speed torque is augmented.

The rotor dynamics, together with the generator inertia, are characterized by the following differential equations:

$$
\left\{\begin{array}{l}
J_{r} \dot{\omega}_{r}=T_{a}-K_{r} \omega_{r}-B_{r} \theta_{r}-T_{\mathrm{ls}} \\
J_{g} \dot{\omega}_{g}-T_{\mathrm{hs}}-K_{g} \omega_{g}-B_{g} \theta_{g}-T_{g} .
\end{array}\right.
$$

The gearbox ratio is defined as

$$
n_{g}=\frac{\omega_{g}}{\omega_{r}}=\frac{T_{\mathrm{ls}}}{T_{\mathrm{hs}}} .
$$




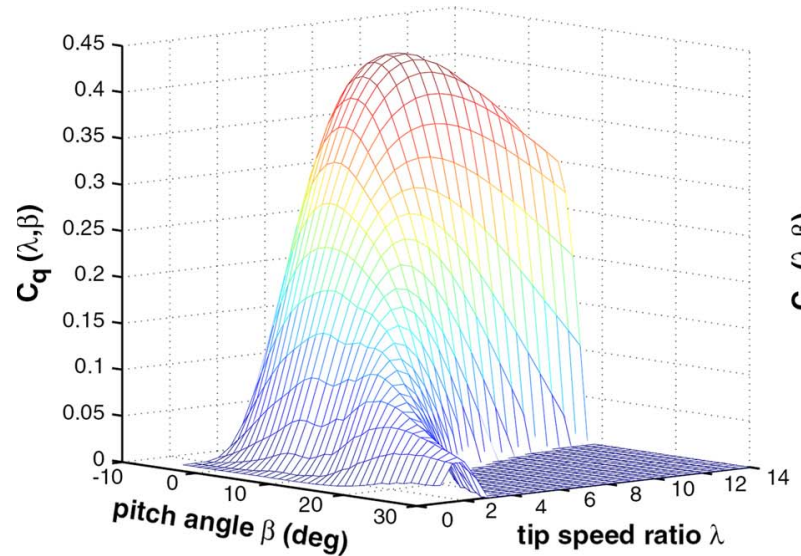

Fig. 4. Wind turbine power and torque coefficients [7].

It comes then that

$$
J_{t} \dot{\omega}_{r}=T_{a}-K_{t} \omega_{r}-B_{t} \theta_{r}-T_{g}
$$

where

$$
\left\{\begin{array}{l}
J_{t}=J_{r}+n_{g}^{2} J_{g} \\
K_{t}=K_{r}+n_{g}^{2} K_{g} \\
B_{t}=B_{r}+n_{g}^{2} B_{g} \\
T_{g}=n_{g} T_{\mathrm{em}} .
\end{array}\right.
$$

Since the external stiffness $B_{t}$ is very low, it can be neglected (the combined inertia of the generator and the rotor is dominating). This leads to represent the drive train as single lumped mass for control purposes. We will then use the following simplified model for control purposes:

$$
J_{t} \dot{\omega}_{r}=T_{a}-K_{t} \omega_{r}-T_{g} .
$$

The generated power will finally be given by

$$
P_{g}=T_{g} \omega_{r}
$$

\section{Robust Control Design}

\section{A. Problem Formulation}

Wind turbines are designed to produce electrical energy as cheaply as possible. Therefore, they are generally designed so that they yield maximum output at wind speeds around $15 \mathrm{~m} / \mathrm{s}$. In case of stronger winds, it is necessary to waste part of the excess energy of the wind in order to avoid damaging the wind turbine. All wind turbines are therefore designed with some sort of power control. This standard control law keeps the turbine operating at the peak of its $C_{p}$ curve

$$
T_{g}=k \omega^{2}, \quad \text { with } \quad k=\frac{1}{2} \pi \rho R^{5} \frac{C_{p \max }}{\lambda_{\mathrm{opt}}^{3}} .
$$

There are two significant problems with this standard control. The first one is that there is no accurate way to determine $k$, particularly since blade aerodynamics can change significantly over time. The second one concerns the fact that the term $J_{t} \dot{\omega}_{r}+K_{t} \omega_{r}$ is neglected, which means that the captured power is supposed to be equal to $T_{g} \omega_{t}$. It is obvious

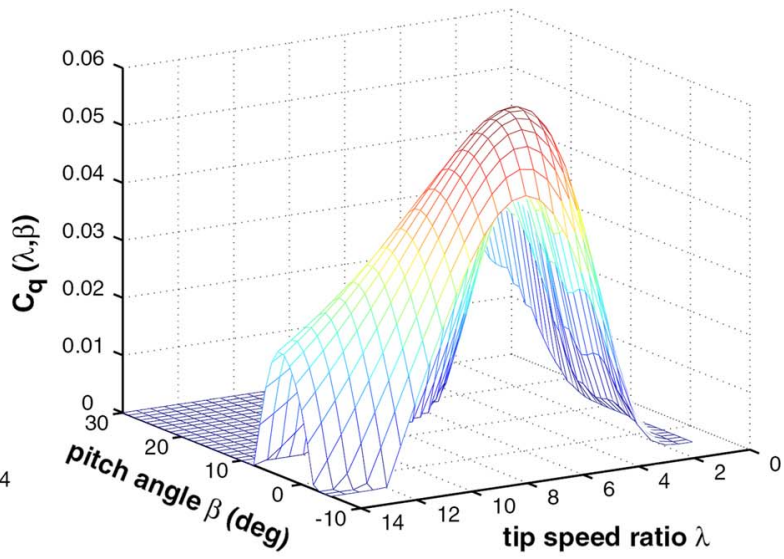

that in many cases, and particularly for turbulent winds, this assumption will not be realistic. Moreover, even when it is assumed that $k$ can be accurately determined via simulation or experiments, wind speed fluctuations force the turbine to operate off the peak of its $C_{p}$ curve much of the time. Indeed, tight tracing the maximum $C_{p}$ would lead to high mechanical stress and transfer aerodynamic fluctuations into the power system. This, however, will result in less energy capture.

The proposed control strategy will therefore solve the second problem. Indeed, the proposed solution to the problem of wind turbine maximum power point tracking (MPPT) control strategy relies on the estimation of the aerodynamic torque using a high-order sliding-mode observer [8], [9]. This estimate is then used to derive a high-order sliding-mode controller that ensures $T_{\text {opt }}$ tracking in finite time.

\section{B. Aerodynamic Torque Observer}

In order to estimate the aerodynamic torque, we will use the supertwisting algorithm [9]. This algorithm has been developed for systems with relative degree 1 to avoid the chattering phenomena. The control law comprises two continuous terms that, again, do not depend upon the first time derivative of the sliding variable. The discontinuity appears only in the control input time derivative.

Let us consider the following observer based on the supertwisting algorithm

$$
\left\{\begin{array}{l}
\dot{\hat{\omega}}=x-K_{t} \omega-\frac{T_{g}}{J_{t}}-A_{1}|\hat{\omega}-\omega|^{\frac{1}{2}} \operatorname{sgn}(\hat{\omega}-\omega) \\
\dot{x}=-A_{2} \operatorname{sgn}(\hat{\omega}-\omega)
\end{array}\right.
$$

and the observation error $e_{\omega}=\hat{\omega}-\omega$; thus, we have

$$
\begin{aligned}
& \dot{e}_{\omega}=-\frac{T_{a}}{J_{t}}+x-A_{1}\left|e_{\omega}\right|^{\frac{1}{2}} \operatorname{sgn}\left(e_{\omega}\right) \\
& \ddot{e}_{\omega}=-\frac{\dot{T}_{a}}{J_{t}}+\dot{u} \text { with } u=x-A_{1}\left|e_{\omega}\right|^{\frac{1}{2}} \operatorname{sgn}\left(e_{\omega}\right) .
\end{aligned}
$$

According to the supertwisting algorithm, the gains $A_{1}$ and $A_{2}$ are chosen as

$$
\left\{\begin{array}{l}
A_{1}>\Phi_{1} \\
A_{2}^{2} \geq \frac{4 \Phi_{1}\left(A_{1}+\Phi_{1}\right)}{\left(A_{1}-\Phi_{1}\right)}
\end{array}\right.
$$




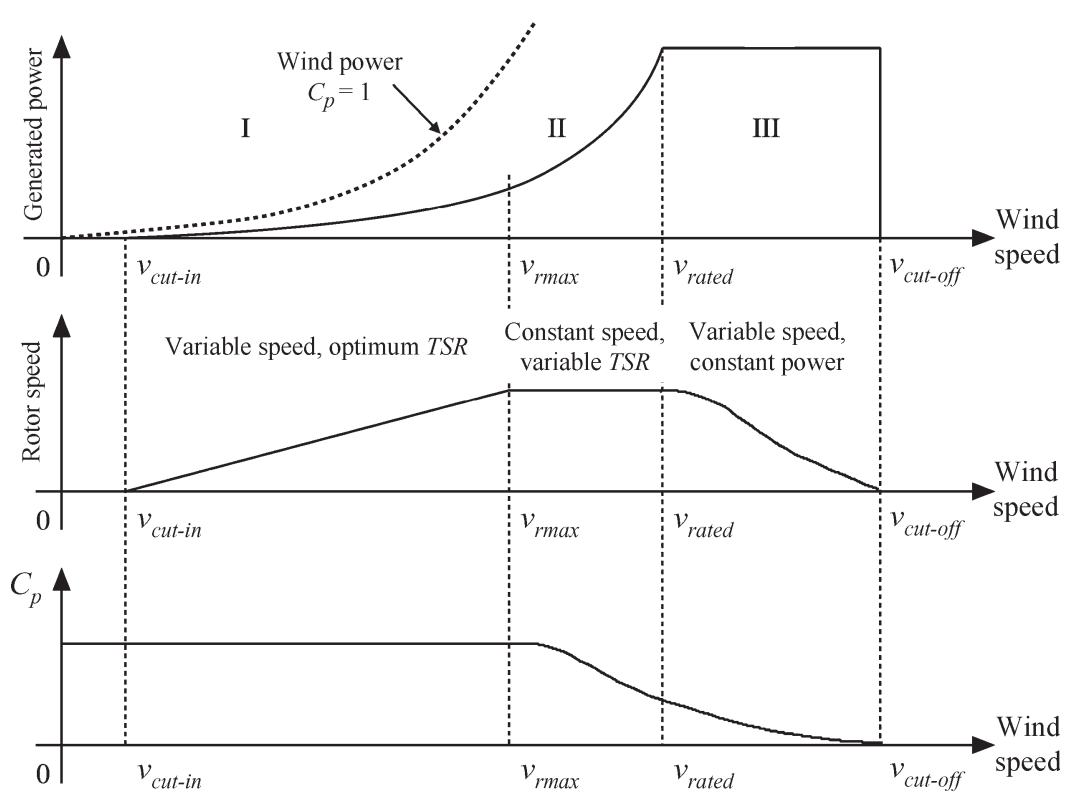

Fig. 5. Optimal efficiency loci depicting the different regions of turbine control.

where $\Phi_{1}$ is a positive constant which satisfies $\left|\dot{T}_{a} / J_{t}\right|<\Phi_{1}$. Thus, we will guarantee the convergence of $e_{\omega}$ and $\dot{e}_{\omega}$ to 0 in a finite time $t_{f}$, and from this, we deduce an estimation of the aerodynamic torque defined by

$$
T_{a}=J_{t} x \quad \forall t>t_{f} .
$$

\section{Proposed Control Strategy}

To effectively extract wind power while at the same time maintaining safe operation, the wind turbine should be driven according to the following three fundamental operating regions associated with wind speed, maximum allowable rotor speed, and rated power [10], [11]. The three distinct regions are shown in Fig. 5, where $v_{r \max }$ is the wind speed at which the maximum allowable rotor speed is reached, while $v_{\text {cut-off }}$ is the furling wind speed at which the turbine needs to be shut down for protection.

In practice, there are two possible regions of turbine operation, namely, the high- and low-speed regions. High-speed operation (III) is frequently bounded by the speed limit of the machine. Conversely, regulation in the low-speed region (II) is usually not restricted by speed constraints. However, the system has nonlinear nonminimum phase dynamics in this region. This adverse behavior is an obstacle to perform the regulation task [10].

A common practice in addressing the control problem of wind turbines is to use a linearization approach. However, due to the stochastic operating conditions and the inevitable uncertainties inherent in the system, such control methods come at the price of poor system performance and low reliability [4], [12]. Hence the need for nonlinear and robust control to take into account these control problems [13]. In this context, sliding-mode control seems to be an interesting approach. Indeed, it is one of the effective nonlinear robust control approaches since it provides system dynamics with an in- variant property to uncertainties once the system dynamics are controlled in the sliding mode [14]. Moreover, it is easy to implement. For wind turbine control, sliding mode should provide a suitable compromise between conversion efficiency and torque oscillation smoothing [15]-[23].

The proposed control strategy combines a second-order sliding-mode observer with a second-order sliding-mode controller. This strategy does not use the wind velocity and avoids the chattering phenomena. With this approach, effective improvements are brought regarding a previously proposed sliding-mode control strategy [23]. It should be noted that this strategy requires only a rotation speed sensor.

The control objective is to optimize the capture of wind energy by tracking the optimal torque $T_{\mathrm{opt}}$.

For that purpose, let us consider the tracking error

$$
e_{T}=T_{\mathrm{opt}}-T_{a}
$$

where $T_{a}$ is deduced from the observer. Then, we will have

$$
\dot{e}_{T}=2 k_{\mathrm{opt}} \omega\left(T_{a}-K_{t} \omega-T_{g}\right)-\dot{T}_{a}
$$

If we define the functions $F$ and $G$ as follows:

$$
\left\{\begin{array}{l}
F=2 k_{\mathrm{opt}} \omega \\
G=2 k_{\mathrm{opt}} \omega\left(T_{a}-K_{t} \omega\right)-\dot{T}_{a}
\end{array}\right.
$$

thus, we have $\ddot{e}_{T}=-F \dot{T}_{g}+\dot{G}$.

Now, let us consider the following high-order sliding-mode controller based on the supertwisting algorithm [9]:

$$
\left\{\begin{array}{l}
T_{g}=y+B_{1}\left|e_{T}\right|^{\frac{1}{2}} \operatorname{sgn}\left(e_{T}\right) \\
\dot{y}=+B_{2} \operatorname{sgn}\left(e_{T}\right)
\end{array}\right.
$$




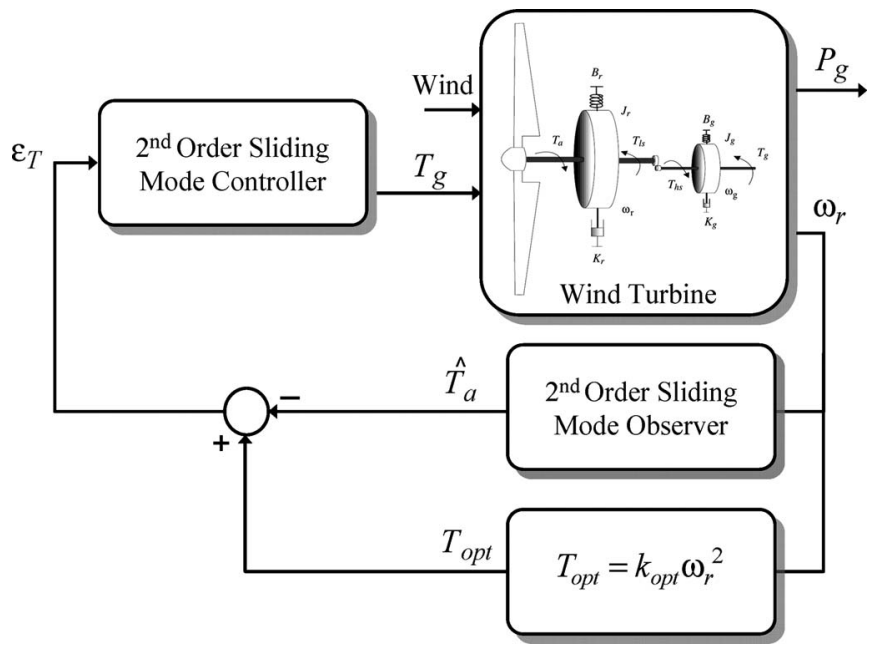

Fig. 6. Proposed control scheme.

where the constants $B_{1}$ and $B_{2}$ satisfy the following inequalities:

$$
\left\{\begin{array}{l}
B_{1}>\frac{\Phi_{2}}{\Gamma_{m}} \\
B_{2}^{2} \geq \frac{4 \Phi_{2} \Gamma_{M}\left(A_{1}+\Phi_{1}\right)}{\Gamma_{m}^{3}\left(A_{1}-\Phi_{1}\right)} \\
|\dot{G}|<\Phi_{2} \\
0<\Gamma_{m} \leq F \leq \Gamma_{M} .
\end{array}\right.
$$

Thus, we can say that there exists a finite time $t_{c}$ so as $T_{a}=T_{\mathrm{opt}}, t>t_{c}$. This means that the control objective is achieved.

The aforementioned proposed wind turbine control strategy is shown in Fig. 6.

\section{VALIDATION RESULTS}

The proposed high-order sliding-mode control strategy has been tested for validation using the National Renewable Energy Laboratory (NREL) FAST (Fatigue, Aerodynamics, Structures, and Turbulence) code.

The FAST code is a comprehensive aeroelastic simulator capable of predicting both the extreme and fatigue loads of two- and three-bladed horizontal-axis wind turbines [24]. This simulator has been chosen for validation because, in 2005, it was evaluated by Germanischer Lloyd WindEnergie and found to be suitable for the calculation of onshore wind turbine loads for design and certification [25]. Indeed, it is proven that the structural model of FAST is of higher fidelity than other codes.

Therefore, this code has been chosen to validate the proposed high-order sliding-mode observer/control approach. It should be noticed that this code is progressively adopted [26].

\section{A. FAST Briefly and Implementation}

During time-marching analysis, FAST makes it possible to control the turbine and model specific conditions in many ways. Five basic methods of control are available: pitching the blades, controlling the generator torque, applying the high-speed shaft
TABLE I

WIND TURBINE CHARACTERISTICS

\begin{tabular}{c|c}
\hline \hline Number of blades & 3 \\
\hline Rotor diameter & $70 \mathrm{~m}$ \\
\hline Hub height & $84.3 \mathrm{~m}$ \\
\hline Rated power & $1.5 \mathrm{MW}$ \\
\hline Turbine total inertia & $4.4532 \times 10^{5} \mathrm{~kg} \mathrm{~m}^{2}$ \\
\hline \hline
\end{tabular}

brake, deploying the tip brakes, and yawing the nacelle. The simpler methods of controlling the turbine require nothing more than setting some of the appropriate input parameters in the turbine control section of the primary input file. Methods of control that are more complicated (that is our case) require writing specific routines, compiling them, and linking them with the rest of the program [27].

An interface has also been developed between FAST and Simulink with Matlab, enabling users to implement advanced turbine controls in Simulink convenient block diagram form.

The FAST subroutines have been linked with a Matlab standard gateway subroutine in order to use the FAST equations of motion in an S-function that can be incorporated in a Simulink model. This introduces tremendous flexibility in wind turbine control implementation during simulation. Generator torque control, nacelle yaw control, and pitch control modules can be designed in the Simulink environment and simulated while making use of the complete nonlinear aeroelastic wind turbine equations of motion available in FAST.

The wind turbine block, as shown in Fig. 7, contains the S-function block with the FAST motion equations. It also contains blocks that integrate the degree-of-freedom accelerations to get velocities and displacements. Thus, the equations of motion are formulated in the FAST S-function but solved using one of the Simulink solvers. The Simulink model should appear as in Fig. 8.

\section{B. Test Conditions}

Numerical validations, using FAST with Matlab-Simulink, have been carried out on the NREL WP 1.5-MW wind turbine which ratings are summarized in Table I [13]. Moreover, the second-order sliding-mode controller chosen constants are as follows: $A_{1}=1 \times 10^{6}, A_{2}=7 \times 10^{6}, B_{1}=10, B_{2}=1000$, and $k_{\mathrm{opt}}=1.6124 \times 10^{5}$.

\section{Validation Results}

In our case, the MPPT strategy is based on the design of second-order sliding-mode controller that ensures the convergence of $T_{a}$ to $k_{\mathrm{opt}} \omega^{2}$ in finite time [23], [28]. Indeed, no particular iterative method is used [29].

Validation tests were performed using FAST wind data shown in Fig. 9. Very good tracking performances are achieved as clearly shown in Figs. 10 and 11. However, it should be mentioned that due to the simplifications of our model, the torque convergence is less good than the rotor speed ones. 


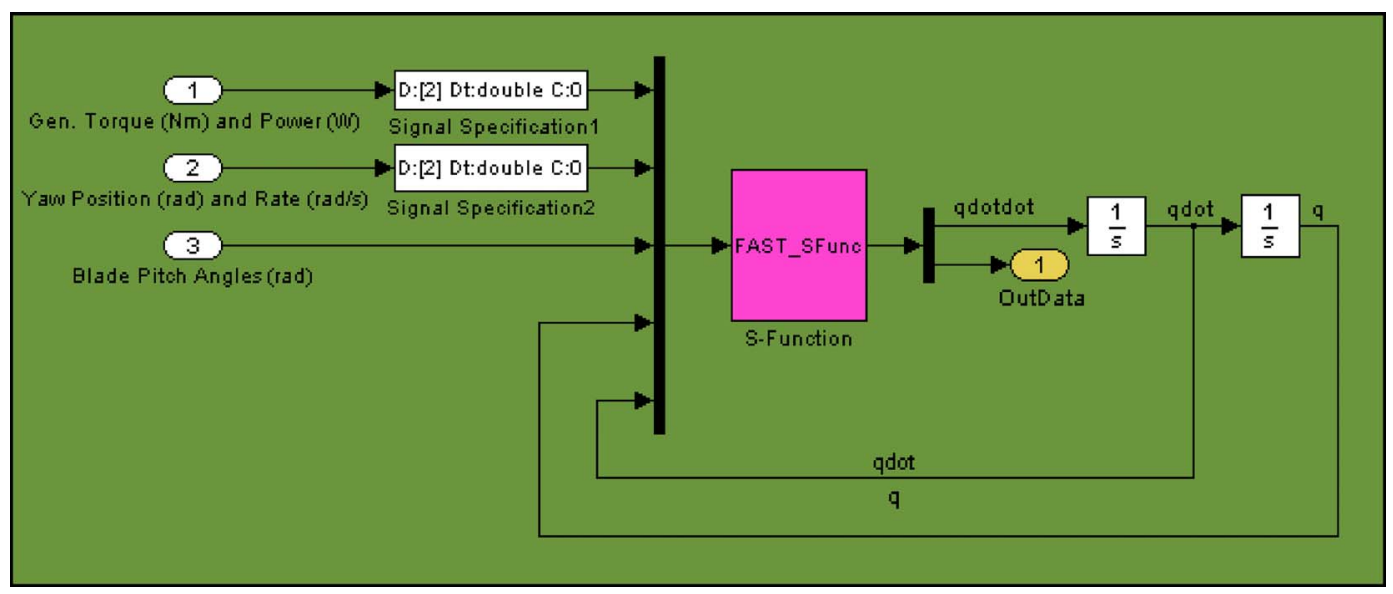

Fig. 7. FAST wind turbine block.

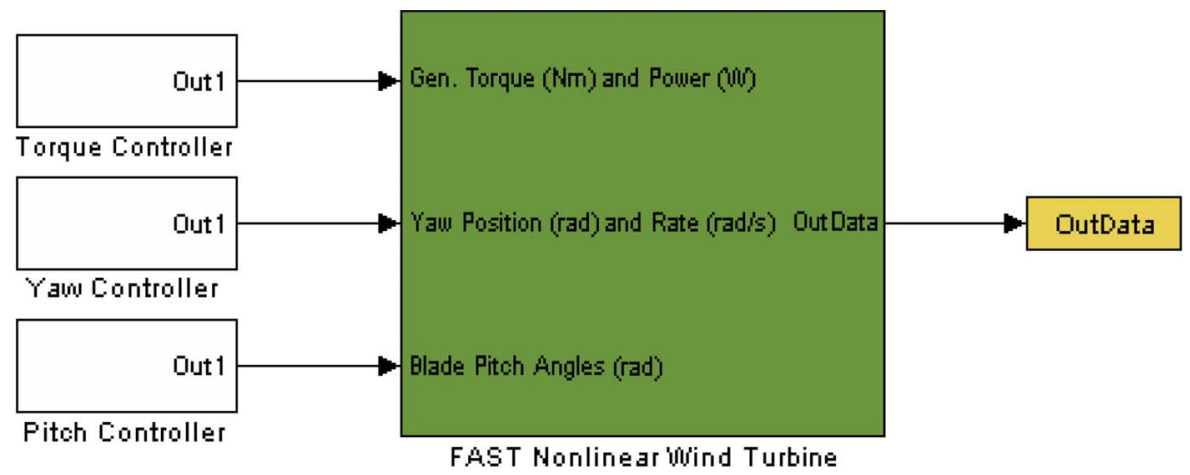

Fig. 8. Simulink model.

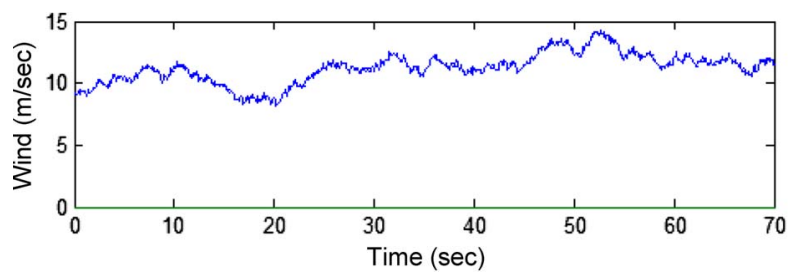

Fig. 9. Wind speed profile.

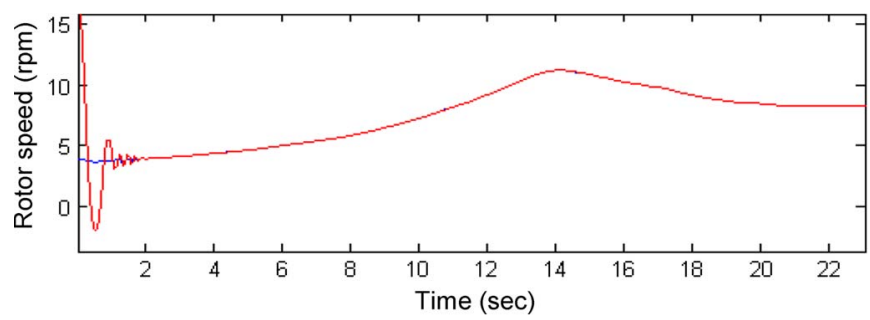

Fig. 10. Rotor speed: (Red) Estimated and (blue) real.

Regarding, the wind turbine outputs, the following results are achieved.

1) As expected, the generator torque $T_{a}$ tracks more efficiently the wind fluctuations than in standard control with almost $2 \%$ error (Fig. 12). This result was also obtained with a previously published technique [23].

2) The rotor speed is very smooth with no chattering as shown in Fig. 13. The proposed high-order sliding-mode

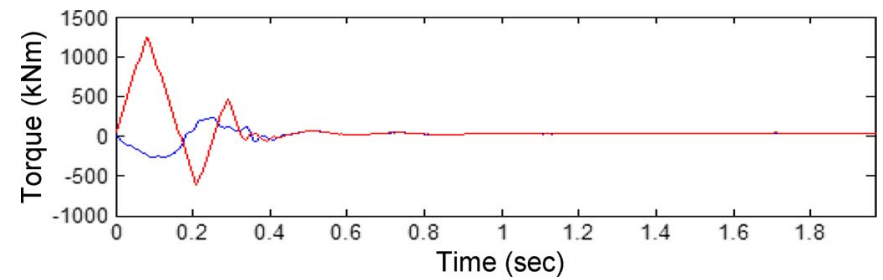

Fig. 11. Aerodynamic torque ( $\left.T_{a}\right)$ : (Red) Estimated and (blue) real.

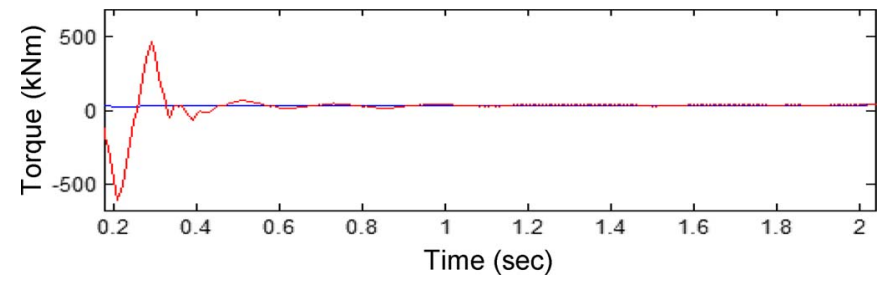

Fig. 12. (Red) Estimated aerodynamic torque $T_{a}$ and (blue) $T_{\mathrm{opt}}$.

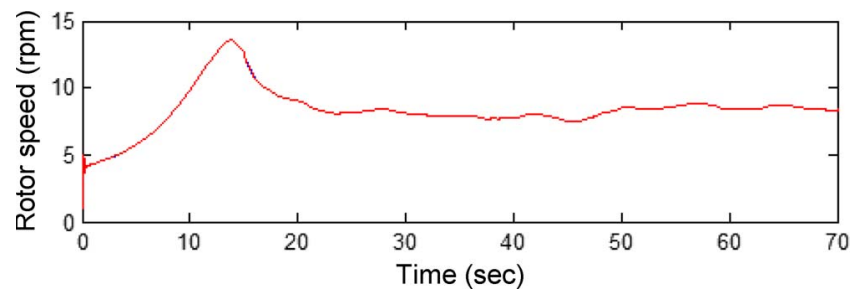

Fig. 13. Rotor speed. 


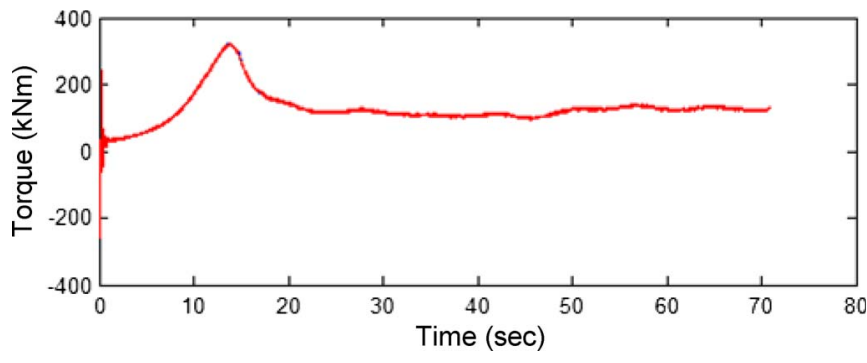

Fig. 14. Estimated aerodynamic torque $\left(T_{a}\right)$.

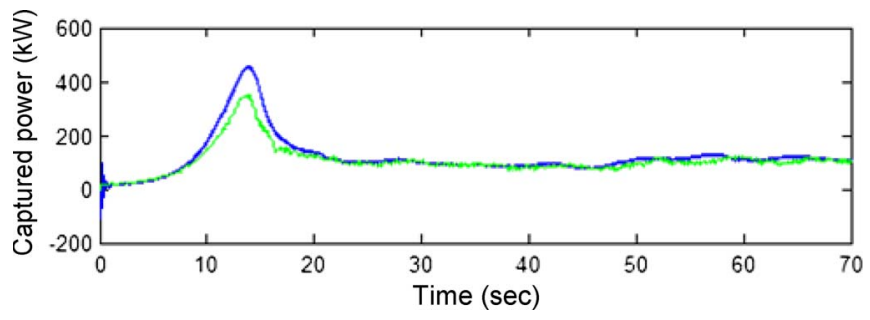

Fig. 15. Captured power: (Green) Standard and (blue) proposed control strategy.

control strategy does not induce increased mechanical stress as there are no strong torque variations. Indeed and as expected, the aerodynamic torque remains smooth (Fig. 14). These result in the reduction of the drive train mechanical stresses and output power fluctuations as shown in Fig. 15.

\section{CONCLUSION}

This paper dealt with the problem of controlling power generation in VSWTs.

For that purpose, a high-order sliding-mode control strategy was proposed to ensure stability in both operation regions and to impose the ideal feedback control solution despite of model uncertainties. The proposed second-order sliding-mode control strategy presents attractive features such as robustness to parametric uncertainties of the turbine and the generator as well as to electric grid disturbances.

The proposed control strategy has been validated using the NREL wind turbine simulator FAST. Validation results show that the proposed control strategy is effective in terms of power regulation. Moreover, the torque generator remains smooth. Indeed, the high-order sliding-mode approach is used so as to produce no chattering in the generated torque. The main advantages of the proposed observer/control algorithm, according to the available literature [5], [11], [20], [22], are its simplicity and robustness against parameter uncertainties and modeling inaccuracies. Moreover, this algorithm gives an efficient estimation of the aerodynamic torque and improves the power generation and the energy quality.

\section{REFERENCES}

[1] R. Thresher, M. Robinson, and P. Veers, "The status and future of wind energy technology," IEEE Power Energy Mag., vol. 5, no. 6, pp. 34-46, Nov./Dec. 2007.

[2] T. Ackermann and L. Soder, "Wind energy technology and current status: A review," Renew. Sustain. Energy Rev., vol. 4, no. 4, pp. 315-374, Dec. 2000
[3] Y. Amirat, M. E. H. Benbouzid, B. Bensaker, R. Wamkeue, and H. Mangel, "The state of the art of generators for wind energy conversion systems," in Proc. ICEM, Crete Island, Greece, Sep. 2006.

[4] Y. D. Song, B. Dhinakaran, and X. Y. Bao, "Variable speed control of wind turbines using nonlinear and adaptive algorithms," J. Wind Eng. Ind. Aerodyn., vol. 85, no. 3, pp. 293-308, Apr. 2000.

[5] B. Boukhezzar and H. Siguerdidjane, "Nonlinear control of variable speed wind turbines for power regulation," in Proc. IEEE CCA, Toronto, ON, Canada, Aug. 2005, vol. 3, pp. 114-119.

[6] E. Bossanyi, Wind Energy Handbook. New York: Wiley, 2000.

[7] B. Boukhezzar, L. Lupu, H. Siguerdidjane, and M. Hand, "Multivariable control strategy for variable speed, variable pitch wind turbine," Renew. Energy, vol. 32, no. 8, pp. 1273-1287, Jul. 2007.

[8] A. Levant and L. Alelishvili, "Integral high-order sliding modes," IEEE Trans. Autom. Control, vol. 52, no. 7, pp. 1278-1282, Jul. 2007.

[9] L. Fridman and A. Levant, "Sliding mode control in engineering," in Higher Order Sliding Modes. New York: Marcel Dekker, 2002, ch. 3, pp. 53-101.

[10] T. Senjyu, R. Sakamoto, N. Urasaki, T. Funabashi, H. Fujita, and H. Sekine, "Output power leveling of wind turbine generator for all operating regions by pitch angle control," IEEE Trans. Energy Convers., vol. 21, no. 2, pp. 467-475, Jun. 2006.

[11] K. E. Johnson, "Adaptive torque control of variable speed wind turbines," National Renewable Energy Lab., Golden, CO, NREL/TP-500-36265, Aug. 2004

[12] A. Mirecki, X. Roboam, and F. Richardeau, "Architecture complexity and energy efficiency of small wind turbines," IEEE Trans. Ind. Electron., vol. 54, no. 1, pp. 660-670, Feb. 2007.

[13] M. M. Hand, K. E. Johnson, L. J. Fingersh, and A. D. Wright, "Advanced control design and field testing for wind turbines at the National Renewable Energy Laboratory," National Renewable Energy Lab., Golden, CO, NREL/CP-500-36118, May 2004.

[14] K. D. Young, V. I. Utkin, and U. Ozguner, "A control engineer's guide to sliding mode control," IEEE Trans. Control Syst. Technol., vol. 7, no. 3, pp. 328-342, May 1999.

[15] R. J. Wai, W. H. Wang, and C. Y. Lin, "High-performance stand-alone photovoltaic generation system," IEEE Trans. Ind. Electron., vol. 55, no. 1, pp. 240-250, Jan. 2008.

[16] Y. Yildiz, A. Sabanovic, and K. Abidi, "Sliding-mode neuro-controller for uncertain systems," IEEE Trans. Ind. Electron., vol. 54, no. 3, pp. 16761685, Jun. 2007.

[17] W. F. Xie, "Sliding-mode-observer-based adaptive control for servo actuator with friction," IEEE Trans. Ind. Electron., vol. 54, no. 3, pp. 1517-1527, Jun. 2007.

[18] H. De Battista and R. J. Mantz, "Dynamical variable structure controller for power regulation of wind energy conversion systems," IEEE Trans. Energy Convers., vol. 19, no. 4, pp. 756-763, Dec. 2004.

[19] F. Valenciaga, P. F. Puleston, and P. E. Battaiotto, "Power control of a solar/wind generation system without wind measurement: A passivity/sliding mode approach," IEEE Trans. Energy Convers., vol. 18, no. 4, pp. 501-507, Dec. 2003.

[20] H. De Battista, R. J. Mantz, and C. F. Christiansen, "Dynamical sliding mode power control of wind driven induction generators," IEEE Trans. Energy Convers., vol. 15, no. 4, pp. 451-457, Dec. 2000.

[21] F. Valenciaga, P. F. Puleston, P. E. Battaiotto, and R. J. Mantz, "Passivity/sliding mode control of a stand-alone hybrid generation system," Proc. Inst. Elect. Eng.-Control Theory Appl., vol. 147, no. 6, pp. 680-686, Nov. 2000.

[22] H. De Battista, P. F. Puleston, R. J. Mantz, and C. F. Christiansen, "Sliding mode control of wind energy systems with DOIG-power efficiency and torsional dynamics optimization," IEEE Trans. Power Syst., vol. 15, no. 2, pp. 728-734, May 2000.

[23] B. Beltran, T. Ahmed-Ali, and M. E. H. Benbouzid, "Sliding mode power control of variable speed wind energy conversion systems," IEEE Trans. Energy Convers., vol. 23, no. 2, pp. 551-558, Jun. 2008.

[24] (Last accessed June 2009). [Online]. Available: http://wind.nrel. gov/designcodes/simulators/fast/

[25] A. Manjock, Design Codes FAST and ADAMS for Load Calculations of Onshore Wind Turbines. Hamburg, Germany: Germanischer Lloyd WindEnergie GmbH, May 26, 2005.

[26] R. Fadaeinedjad, M. Moallem, and G. Moschopoulos, "Simulation of a wind turbine with doubly fed induction generator by FAST and Simulink," IEEE Trans. Energy Convers., vol. 23, no. 2, pp. 690-700, Jun. 2008.

[27] J. M. Jonkman and M. L. Buhl, "FAST user's guide," National Renewable Energy Lab., Golden, CO, NREL/EL-500-29798, 2005. 
[28] I. S. Kim, M. B. Kim, and M. J. Youn, "New maximum power point tracker using sliding-mode observer for estimation of solar array current in the grid-connected photovoltaic system," IEEE Trans. Ind. Electron., vol. 53, no. 4, pp. 1027-1035, Jun. 2006

[29] E. Koutroulis and K. Kalaitzakis, "Design of a maximum power tracking system for wind-energy-conversion applications," IEEE Trans. Ind. Electron., vol. 53, no. 2, pp. 486-494, Apr. 2006.

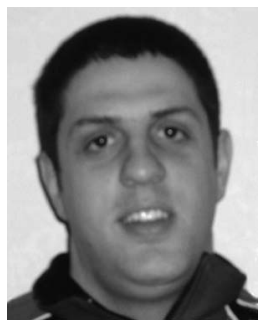

Brice Beltran was born in Arles, France, in 1981. $\mathrm{He}$ received the Engineer degree in electrical engineering from the Ecole Nationale Supérieure d'Ingénieurs des Etudes et Techniques d'Armement, Brest, France, in 2006. He is currently working toward the Ph.D. degree in the Laboratoire Brestois de Mécanique et des Systèmes, University of Brest, Brest, focusing on wind energy conversion systems' advanced control and fault-tolerant control.

In 2006, he was with the Délégation Générale pour information systems.

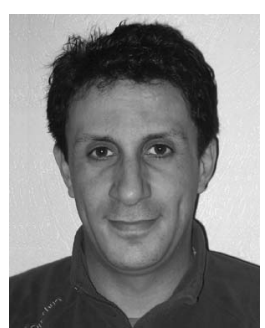

Tarek Ahmed-Ali was born in Algiers, Algeria, in 1972. He received the B.Sc. degree in electrical engineering from the Ecole Nationale Polytechnique of Algiers, Algiers, in 1994, the M.Sc. degree in electrical and computer engineering from the University of Paris VI, Paris, France, in 1995, and the Ph.D. degree in electrical and computer engineering from the University of Paris Sud, Paris, in 1998.

In 1998, he was with the University of Paris XIII, Paris, as a Teaching and Research Assistant. In 1998, he then moved to the Ecole Centrale de Lille, Lille, France, also as a Teaching and Research Assistant. In 2000, he was appointed as a Research and Development Engineer with SNCF (the French Railway Corporation). In 2002, he was appointed to a lectureship in control engineering with the Ecole Nationale des Ingénieurs des Etudes et Techniques de l'Armement of Brest, France. He is currently with the Laboratoire Brestois de Mécanique et des Systèmes, University of Brest, Brest. His main research interests include sliding-mode control, nonlinear observers, and fault-tolerant control and diagnosis in the field of ac drives.

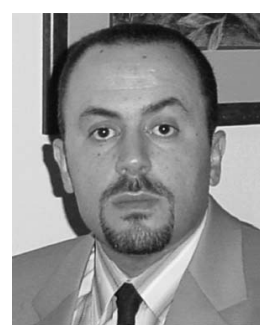

Mohamed El Hachemi Benbouzid (S'92-M'95SM'98) was born in Batna, Algeria, in 1968. He received the B.Sc. degree in electrical engineering from the University of Batna, Batna, in 1990, the M.Sc. and Ph.D. degrees in electrical and computer engineering from the National Polytechnic Institute of Grenoble, Grenoble, France, in 1991 and 1994, respectively, and the Habilitation à Diriger des Recherches degree from the University of Picardie "Jules Verne", Amiens, France, in 2000.

After receiving the Ph.D. degree, he joined the Professional Institute of Amiens, University of Picardie "Jules Verne", where he was an Associate Professor of electrical and computer engineering. In September 2004, he was with the University Institute of Technology (IUT) of Brest, University of Western Brittany, Brest, France, as a Professor of electrical engineering. He is currently with the Laboratoire Brestois de Mécanique et des Systèmes, University of Brest. His main research interests and experience include analysis, design, and control of electric machines, variable-speed drives for traction and propulsion applications, and fault diagnosis of electric machines.

Prof. Benbouzid is a Senior Member of the IEEE Power Engineering, Industrial Electronics, Industry Applications, Power Electronics, and Vehicular Technology Societies. He is an Associate Editor of the IEEE TRANSACTIONS ON ENERGY CONVERSION, the IEEE TRANSACTIONS ON INDUSTRIAL ELECTRONICS, the IEEE TRANSACTIONS ON VehICULAR TECHNOLOGY, and the IEEE/ASME TRANSACTIONS ON MECHATRONICS. 